\title{
Invasive Cervical Resorption: An Insidious Form of External Tooth Resorption
}

\author{
Dr. P.V. Samir ${ }^{1}$, Dr. Kanika Singh Dhull ${ }^{2}$, Dr. Brahmananda Dutta ${ }^{3}$, \\ Dr. Anandamoy Bagchi ${ }^{4}$, Dr. Tulika Verma ${ }^{5}$ \\ Kalinga Institute of Dental Sciences, Bhubaneswar
}

\begin{abstract}
Invasive cervical resorption (ICR) is an unusual form of external root resorption which initiates below the epithelial attachment and coronal aspect of supporting alveolar process to be precise zone of connective tissue attachment. It has an unclear etiology leading to its non diagnosis or misdiagnosis as a pink tooth (internal resorption).

Dr. Geoffrey Heithersay contributed immensely in diagnosis and clinical classification of ICR into 4 stages based on its clinical, pathological and radiological finding and potential pre-disposing factors. These lesions can be treated by either non surgical or surgical intervention depending upon the access of the lesion or its progress towards pulp. Management of lesions of ICR should be treated with a primary objectives of i) Inactivation of all resorbing tissues and ii) Reconstruction or resorptive tooth defect by an ideal restorative material or biological systems. Earlier is the diagnosis more successful is the outcome of management of invasive cervical resorption. This article reviews on diagnosis of ICR, correlating it with its clinical, radiological and histo-pathological findings along with management in brief.
\end{abstract}

Keywords: Cervical resorption, External resorption, Invasive lesion, Tooth resorption

\section{Introduction}

Tooth resorption is described as loss of hard dental tissues like cementum and dentin due to odontoclastic activity. Root resorption is the most common form of tooth resorption which arises as a late complication following any luxation injuries. Root resorption based upon their location can be classified as External root resorption (Root surface resorption) and Internal root resorption (Root canal resorption). External resorption can be physiological or pathological. The pathological forms of external root resorption can be classified into 5 forms: external surface resorption, external inflammatory root resorption, external replacement resorption (ankylosis), external cervical resorption and transient apical breakdown. External cervical resorption is also known as Invasive cervical resorption: an aggressive, subtle and rare form of external tooth resorption of any permanent tooth. ${ }^{1}$

Invasive cervical resorption (ICR) is defined as a localised resorptive process that involves the surface of root below epithelial and coronal aspect of supporting alveolar process namely the zone of connective tissue attachment. ${ }^{2}$ It can be characterised by its invasive nature and cervical location leading to progressive and destructive loss of tooth structure. The affected tooth`s crown shows pinkish discoloration due to enamel and coronal dentin resorption and its replacement with highly vascular tissue. ${ }^{3}$ Similar resorptive processes are seen in different other locations such as Invasive coronal resorption: enamel defect in the crown of erupting tooth and Invasive radicular resorption: resorption involving more apical source.

Mueller \& Rony in 1930 first described the condition of idiopathic cervical resorption. Term invasive cervical resorption was first coined by Dr. Geoffrey Heithersay. Invasive cervical resorption continues to be misdiagnosed as internal resorption till date due to pink spot lesion of internal resorption described by Gaskill (1894) and Mummery (1920). ${ }^{4,5}$ Researchers and clinicians over the years have labelled this Invasive cervical resorption in various other forms like: odontoclastoma, idiopathic external resorption, peripheral cervical resorption, cervical external resorption, extracanal invasive resorption, supraosseous extracanal invasive resorption, peripheral inflammatory root resorption, cervical resorption, subepithelial inflammatory root resorption, burrowing resorption, late cervical resorption, periodontal infection resorption, fibrous dysplasia of teeth.

\section{Etiology}

ICR is a rare, insidious and aggressive form of tooth resorption with idiopathic etiology. Literature is still biased on the resorptive process in ICR which may result either from sulcular microorganisms activating pure inflammation or by benign proliferative fibroosseous / fibrovascular disorder where microorganisms have no role but are secondary invaders. This dilemma in literature signifies idiopathic etiology of ICR. Based upon etiology of external resorption it may be classified into (1) Trauma induced tooth resorption (2) Infection 
induced tooth resorption and (3) Hyperplastic invasive tooth resorption. ICR is a form of hyperplastic invasive tooth resorption resulting in loss of cementum and dentine by odontoclastic type of action. ${ }^{7}$

\section{Pathogenesis}

Three factors necessary for a dental resorption to occur are : blood supply, breakdown or absence of protective layer and stimulus. Incase of ICR cementum is an external protective layer while predentin of pulp is innermost layer. Unclear etiology and pathogenesis of ICR leads to a hypothesis claiming the local discontinuity in protective layer of radicular cementum allowing the access of osteoclasts in the subjacent dentin. ${ }^{8}$

The pathogenesis of the ICR begins with the damage to cementum right beneath the epithelial attachment. It further progresses to resorb cementum, enamel and dentin replacing it with the fibrovascular tissue derived from periodontal ligament. ${ }^{6,910}$ Microscopic analysis of cervical region of affected tooth reveals frequent gaps in the cementum, exposing the underlying mineralised dentin for vulnerable osteoclastic activity in root. Voids in the cementum occur frequently in cervical root areas near cementoenamel junction. ${ }^{7}$

Either the damage or deficiency to the protective layer of cementum apical to gingival epithelial attachment exposes the root. The exposed radicular dentin around cervical area may lead to root surface colonization by osteoclast like cells. This osteoclastic action in area of radicular dentin may eventually result in hyperplastic resorptive lesion containing fibroosseous tissue.

A well vascularised granulation tissue containing activated odontoclasts invades dentin and forms branched resorptive channels encircling the pulp cavity, unable to penetrate across the innermost dentin. ${ }^{8}$ The inability to penetrate across the innermost dentin is attributed to resorption inhibitor present in predentin. This results spread of resorption in an apico-coronal direction circumferentially along and around the root canal as soon as it reaches the predentin. As the lesion grows larger bone or cementum like hard tissue adheres to the resorbed dentin surface in parts forming a fine trabeculae pattern within granulation tissue.

\section{Predisposing/ risk factors:}

Various factors such as: intracoronal bleaching, orthodontic treatment, trauma, orthognathic and dentoalveolar surgeries, periodontal treatment, developmental defects, bruxism, interproximal stripping and restoration etc have a potency of causing ICR either solely or in combination. Harrington \& Natkin (1979) documented intracoronal bleaching as the most potent risk factor followed by other factors like trauma, orthodontics, orthognathic surgeries etc. ${ }^{11,12}$

Heithersay in his study on 222 patients with a total of 257 ICR affected teeth analysed the potency of risk factors in causing it solely or in combination among themselves. His analysis shows orthodontics as the most common sole factor in causing ICR in $47(21.2 \%)$ patients with 62 affected teeth followed by intracoronal bleaching in 33(14.9\%) patients, trauma in 31(14\%) patients with 39 affected teeth and periodontal surgeries in $13(5.9 \%)$ patients. Other factors had a very low incidence of solely causing an ICR. Bleaching in combination with trauma was a cause in $2(0.9 \%)$ patients while bleaching with orthodontics was responsible in $4(1.8 \%)$ patients. ${ }^{13}$

V. Gunst et al (2010) reported 2 cases of ICR which had playing a wind instrument as a potential etiological factor. The whilst mechanism in playing a wind pipe generates the pressure directly hitting the anterior teeth which may be a causative factor of ICR. ${ }^{14}$

\section{Clinical and radiographical features:}

\section{Discussion}

Early diagnosis of ICR is often difficult because of its variable clinical presentation. The pink colour discoloration of crown may be an alerting feature of an extensive ICR ${ }^{15}$ G. Heithersay came up with a clinical classification of ICR to provide a better clinical guide for its assessment. The lesions of ICR were categorised into four classes: ${ }^{3}$

Class 1- A small invasive resorpive lesion just near the cervical area with shallow penetration into coronal dentin.

Class 2- A well defined invasive resorptive lesion that has penetrated through the coronal dentin and approximating the pulp. Lesion may have slight extension into radicular dentin.

Class 3- Deeper invasion of resorptive lesion from coronal dentin extending till coronal third of radicular dentin. Class 4- A large invasive resorptive lesion that has extended beyond coronal third of radicular dentin.

\section{Class 1:}

Early lesions of ICR are asymptomatic with a slight irresgularity on cervical surface of tooth near gingival contour. It also may be associated with soft tissue to induce slight bleeding on probing. ${ }^{6}$ The affected tooth will have a positive response to vitality tests. Radiograph reveals a small, diffused radiolucency at cervical 
region of tooth with poorly defined border of defect. Pulpal canal walls are vsible running vertically through the radiolucent lesion indicating thee lesion lying on external surface of root. ${ }^{19}$

Class 2:

The invasive lesion of ICR in Class II are generally asymptomatic and may have sensitivity or mild pain as the lesion resorbs cementum, dentin and approximates the pulp chamber space. The pulpitis symptoms may develop when the resorption penetrates through predentin and in addition invaded by microorganisms. The affected tooth shows a pinkish discoloured crown. Radiograph reveals an amazing,extensive, irregular radiolucency that extends from cervical area aof tooth crown and forward till the root canal outline. The proximal lesion of Class II ICR exhibits a radioopaque line bordering the pulp space.

Class 3:

The invasive resorptive lesion in ICR Class III extends till the coronal third of radicular dentin. The affected tooth shows pinkish discoloration along with cavitation of overlying enamel. These teeth are generally asymptomatic with rare cases of pain symptoms until superimposed by pulpal or periodontal infection. Radiograph reveals the lesion having a moth eaten or irregular mottled appearance. A radiopaque line demarcates the outline of root canal from the adjacent irregular radiolucency. The irregular radiolucency runs vertically down sparing the pulp chamber till coronal third of a radicular dentin.

Class 4:

This severe invasive resorptive process extends beyond the coronal third of radicular dentin till apical third. Pinkish discoloration is seen in crown at cervical region with overt signs and symptoms of acute periodontal infection. Radiograph reveals the lesion having an irregular outline of resorptive process in tooth crown and radiolucent lines extending till the apical third of root along the pulp canal space. ${ }^{3,6}$

\section{Histopathological features:}

There are variations in the histopathological features of ICR depending upon different stages of its progress. Mass of fibrous tissue, numerous blood vessels and resorbing clastic cells adjoining the dentin surface are the chief contents in the early stages of resorption. Inflammation free pulp is separated from actively resorbing tissue by a thin layer of dentin and predentin. The resorbing clastic cells at the dentin interface are mostly mononuclear but sometimes may be multinucleated. The early lesions containing fibrovascular tissue progress into fibroosseous lesion in (Class II) by the deposits of ectopic bone like calcifications in both the resorbing tissue and on the resorbed dentin surface. ${ }^{6}$

The protective predentin is responsible for asymptomatic nature of earlier stages of ICR. Noncollagenous, organic matrix of predentin acts as a resorption inhibitor preventing progress of resorption into pulp. Predentin is devoid of acute and chronic inflammatory cells but microbial invasion into the resorbing lesion can develop pulpitis. ${ }^{16}$

The radicular tooth structure with extensive resorptive defect of Class III ICR contains a mass of fibroosseous and bone like tissue deposited at the base of defect on resorbed dentin. There are infiltrating channels known as delta channels containing soft tissue and communicating with periodontal ligament to increase further potential of resorption. Cross sectional view of tooth reveals an intact pulp chamber encircled by fibroosseous tissue replacing normal tooth structure. Presence of minimal to moderate inflammatory cellular infiltrate is seens in some regions along with irregular calcified deposits on the resorbed areas.

Authors resemble identity among ICR and progressive inflammatory root resorption due to presence of inflammatory cells, multinucleated clast cells, granulation tissue and resorption lacunae in both tooth and the bone. ${ }^{17,18}$

The Class IV lesion of ICR extends beyond coronal third of radicular dentin till apical third. Cross sectional view shows extensive resorption of tooth structures including the pulp and its replacement by calcified tissue and spaces containing fibrovascular tissue. Inflammatory cells cannot be seen in this lesion unless supervened by microbial infection.

\section{Diagnosis}

Early diagnosis will result in more favourable outcome of treatment. Misdiagnosis of the nature of this lesion may lead to treatment failure resulting in progressive resorption and finally loss of tooth. Mostly, the Class 1 lesion owing to its miniature size and location beneath the gingival attachment are often not detected. A small radiolucency on cervical area may be an initial hint of the lesion. Clinical examination may present a slight irregularity in the gingival contour which bleeds on probing. Routine dental examinations rarely detect the early lesions of ICR. Asymptomatic nature of these early lesions synergise the difficulty level in detection of the 
Class 1 lesions. Pulp testing is of no use because of unaffected pulp. Radiographically, early Class 1 lesion can be misdiagnosed as a Class $\mathrm{V}$ carious lesion, internal resorption or a cervical burnout of a radiograph.

Class 2 lesions show more evident clinical signs like pinkish discoloration on anterior tooth. The discoloration is attributed to the translucency of enamel, beneath which lies a reddish granulation tissue that replaces the resorbed radicular dentin by osteoclastic activity. Large Class 2, Class 3 or Class 4 proximal lesions on bitewing radiographs are often misdiagnosed by dentist as a carious lesion or internal resorption as pulpal outline is clearly visible.

Misdiagnosis of a carious lesion or internal resorption can be ruled out by a typical pattern of irregular radiolucency and radioopaque outline of protective predentin and varying angulations of radiograph like "off angle" radiograph. Location of Class 1 lesions can be determined by use of SLOB rule or Clark's rule radiography.

Advancement in aids of investigations have always been a boon to various diagnosis. 3D imaging by CBCT has been preferred over 2D imaging of an $\mathrm{x}$ ray in dentistry for perfection in diagnosis of various disorders and lesions. 3 Dimensional imaging of CBCT in all 3 planes: frontal/coronal, saggital and axial plane determine the exact location and extension of ICR lesion with a definitive accuracy. X ray imaging reveals the changes in root canal with no clarity in actual extent and location of the lesion. 3D CBCT aids in possible root canal communication with exact location and extent of the lesion. ${ }^{19}$

Asymptomatic tooth, pulp tests within normal limits, ICR defect moving with varying $\mathrm{X}$ ray angulations, intact protective radiopaque pulpal wall, portals of entry near osseous crest which are difficult to locate clinically are the specific diagnostic signs indicating the lesion to be an ICR.

\section{Management}

Treatment of ICR should be planned immediately after its diagnosis with prior explanation to the patient. Dr. Heithersay classified severity of ICR in simplified explainable way to the patient that will help them realise the need of future required dental treatment. Depending upon the class of ICR it may be managed either by non surgical or surgical intervention with vital objectives of: inactivation of all active resorbing tissue and reconstruction of the resorptive defect either by placement of suitable filling material or by use of biological systems such as membranes to retain the aesthetic and health of tooth in a long term basis.

Prior to treatment of lesion local anaesthesia is administered with proper isolation of the operative field and glycerol application for the protection of adjacent soft tissues.

The resorptive lesions of ICR was cleaned by solutions like: $3 \% \mathrm{NaOCl}, \quad 17 \%$ Ethylenediaminetetraacetic acid (EDTA), Trichloroacetic acid (TCA), Mosel`s solution (72\% Ferric sulphate+ sulphuric acid) for 2-3 minutes. These solutions have antibacterial effect, organic tissue fixation and regenerative potential of dentin. ${ }^{20,21}$

Class 1 lesions mostly require debridement of affected tissue followed by restoration of the lesion. Class 2 , Class 3 and 4 lesions may require endodontic therapy when the lesion is approximating to pulp and at a risk of perforation while removing a granulation tissue..$^{22,23}$

In case of inaccessibility of the lesion in the cervical third area in oral cavity a surgical intervention is required. The orthodontic extrusion of the affected tooth or apically positioned flap may be carried out with a compromised aesthetics.

In lesions where portal of resorptive defect is in the bone intentional replantation of the affected tooth is done after endodontically treating it and restoring the lesion area with a bio compatible material.

Treatment plan for a generalised progressive resorption involving large number of teeth in multiple quadrants is a challenge in itself. It lacks a specific treatment protocol due to its rare incidence. Moody et al, Kerr et al indicated the extraction of teeth with such lesions where it has progressed to a point of causing a crown fracture and its replacement by a complete denture. ${ }^{24,25}$. Multiple treatment options in such lesions include: 1) Episodic extraction and replacement of fractured teeth. 2) Early surgical intervention with exposure and curettage of lesions, endodontic treatment of tooth and its restoration with glass inomer cement. 3) Crown resection with root submergence for preserving alveolar bone integrity and prosthesis replacement. ${ }^{26}$ 4) Implant placement after extracting the affected tooth and bone augmentation in case of a vertical bone loss. 5) Complete denture after extraction of all teeth. 6) Use of bisphosphonates to cease resoption.

Restoration after cleaning and debridement of lesion or endodontic treatment as required is of prime importance to prevent the further microleakage or sippage of saliva and crevicular fluids back into the cleaned area. Classical restorative materials like silver amalgam, glass ionomer cement, resin based composites have been reported in many several cases of ICR as a restorative material. The lesion as discussed is mostly into the cervical area extending beyond gingival margins with increased moisture contamination of blood, saliva and crevicular fluids. But all these restorative materials are moisture sensitive which may affect their final setting or expansion of restorative material leading to the dislodgement of these materials and long term failures. Newer 
advanced restorative materials like calcium enriched mixture (CEM) biodentine and MTA (mineralised trioxide aggregate) have rose to the occasion with properties like better marginal adaptability, higher tensile and compressive strength, promote remineralisation, biocompatibility and above all they favour setting in moisture contamination. Thus, biodentine, CEM and MTA can be considered as ideal restorative material for an ICR affected tooth. ${ }^{27}$

\section{Cases of invasive cervical resorption reported in literature:}

\begin{tabular}{|c|c|c|}
\hline $\begin{array}{l}\text { AUTHOR AND } \\
\text { YEAR }\end{array}$ & CASES REPORTED & FINDINGS \\
\hline Gaskill JH (1894) & ----- & $\begin{array}{l}\text { Was first to misdiagnose and misunderstand } \\
\text { ICR as internal resorption }\end{array}$ \\
\hline $\begin{array}{l}\text { Mummery } \quad \text { JH } \\
(1920)^{5}\end{array}$ & ------ & $\begin{array}{l}\text { Pink spot lesions on the affected tooth led to the } \\
\text { misdiagnosis of ICR lesion as internal } \\
\text { resorption. }\end{array}$ \\
\hline $\begin{array}{ll}\text { Harrington } & \& \\
\text { Natkin }(1979) & \end{array}$ & $\begin{array}{l}2 \text { cases } \\
14 \text { yr old girl, } 21 \text { yr old man }\end{array}$ & $\begin{array}{l}\text { Intra coronal bleaching the most evident } \\
\text { predisposing factor of ICR }\end{array}$ \\
\hline $\begin{array}{lll}\begin{array}{l}\text { Moskow } \\
(1989)^{29}\end{array} & \text { et } & \text { al } \\
\end{array}$ & 2 cases & $\begin{array}{l}\text { Found ICR in association with patients having } \\
\text { oxalosis and Hyperoxalouria }\end{array}$ \\
\hline $\begin{array}{lr}\text { Frank } & \& \\
\text { Torabinejad } & (1998) \\
22\end{array}$ & ------- & $\begin{array}{l}\text { Intentional replantation as an alternative in } \\
\text { management of aggressive ICR lesions } \\
\text { followed by debridement and root canal } \\
\text { treatment if required. }\end{array}$ \\
\hline $\begin{array}{l}\text { Heithersay } \\
\text { (1999) }\end{array}$ & 222 patients 257 teeth & $\begin{array}{l}\text { Categorised various predisposing factors solely } \\
\text { or in combination with others causing ICR. } \\
\text { Solo factors: Intracoronal bleaching (17 } \\
\text { patients), orthodontic treatment ( } 47 \text { patients), } \\
\text { trauma ( } 31 \text { patients), periodontal surgery (13 } \\
\text { patients) }\end{array}$ \\
\hline $\begin{array}{l}\text { Geoffrey S. } \\
\text { Heithersay (1999) }\end{array}$ & $\begin{array}{l}101 \text { teeth in } 94 \text { patients } \\
\text { having Class } 1 \text { to Class } 3 \\
\text { lesions }\end{array}$ & $\begin{array}{l}\text { Treatment by topical application of } \\
\text { Trichloroacetic acid followed by thorough } \\
\text { curettage, non surgical root canal treatment if } \\
\text { required and restoration of resorptive lesion } \\
\text { with Glass ionomer cement }\end{array}$ \\
\hline Liang et al (2003) ${ }^{31}$ & 5 cases & $\begin{array}{l}\text { Association of ICR lesions in patients with } \\
\text { hormonal abnormalities but still unclear about } \\
\text { these abnormalities as initiating factors or } \\
\text { contributing factors. }\end{array}$ \\
\hline \multirow[t]{4}{*}{$\begin{array}{l}\text { Geoffrey } . \text { S. } \\
\text { Heithersay }(2004)^{3}\end{array}$} & $\begin{array}{l}2 \text { cases: } 22 \text { yr old male } \\
\text { involving both max central } \\
\text { incisors and } 17 \mathrm{yr} \text { old male } \\
\text { with lesion on mandibular } 1^{\text {st }} \\
\text { molar }\end{array}$ & $\begin{array}{l}\text { Had a history of extensive orthodontic } \\
\text { treatment. Radiographically class } 2 \text { ICR lesion } \\
\text { was similar to that of caries with slightly more } \\
\text { irregular radiolucency. } \\
\text { Radiopaque line of demarcation between } \\
\text { irregular and mottled image of resorptive lesion } \\
\text { and that of intact pulp }\end{array}$ \\
\hline & $\begin{array}{l}28 \text { yr old male involving max } \\
\text { left central incisor }\end{array}$ & $\begin{array}{l}\text { Had a history of dental trauma. Crown } \\
\text { displayed a pinkish discoloration in cervical } \\
\text { region. Class } 4 \text { lesion showing irregular outline } \\
\text { of resorptive process of tooth with radiolucenct } \\
\text { lines extending from crown into the apical third } \\
\text { of root along the pulp space }\end{array}$ \\
\hline & $\begin{array}{l}2 \text { cases of } 24 \text { yr old and } 19 \mathrm{yr} \\
\text { old male patients }\end{array}$ & $\begin{array}{l}\text { Had a history of cricket ball trauma and } \\
\text { orthodontic treatment respectively. } \\
\text { Affected tooth in both the cases were } \\
\text { asymptomatic. Symptoms rarely occur in Class } \\
3 \text { lesions unless superimposed by pulpal or } \\
\text { periodontal infections }\end{array}$ \\
\hline & $\begin{array}{l}35 \mathrm{yr} \text { old female with lesion } \\
\text { on max left central incisor }\end{array}$ & $\begin{array}{l}\text { ICR was associated with localised gingival } \\
\text { infection }\end{array}$ \\
\hline $\begin{array}{l}\text { Neely \& Gordon } \\
(2007)^{30}\end{array}$ & 2 cases in father and son & $\begin{array}{l}\text { Reported multiple ICR in both describing the } \\
\text { familial pattern of idiopathic ICR. }\end{array}$ \\
\hline $\begin{array}{l}\text { R. Pace eat al } \\
(2008)^{34}\end{array}$ & 2 cases & $\begin{array}{l}\text { Used MTA (Mineralised trioxide aggregate) for } \\
\text { restoration of the resorptive defect of an ICR } \\
\text { lesion }\end{array}$ \\
\hline $\begin{array}{l}\text { V.S.H. Yu, H.H. } \\
\text { Messer (2010) }\end{array}$ & 33 yr old Chinese male & $\begin{array}{l}\text { Generalised cervical resorption with no } \\
\text { contributory social/familial/medical history. } \\
\text { CBCT revealed involvement of cervical } \\
\text { surfaces of all teeth with lesions overextending } \\
\text { into coronal surface undermining enamel }\end{array}$ \\
\hline
\end{tabular}




\begin{tabular}{|l|l|l|}
\hline $\begin{array}{l}\text { V. Gunst et al } \\
(2011)^{14}\end{array}$ & $\begin{array}{l}2 \text { cases of icr in maxillary } \\
\text { incisors }\end{array}$ & $\begin{array}{l}\text { Pressure trauma by playing wind instrument } \\
\text { was considered as the significant etiologic } \\
\text { factor }\end{array}$ \\
\hline $\begin{array}{l}\text { Karla de Faria } \\
\begin{array}{l}\text { Vasconceleos et al } \\
(2012)^{19}\end{array}\end{array}$ & $\begin{array}{l}\text { 2 cases of caucasian 25yr old } \\
\text { male and 22 yr old female }\end{array}$ & $\begin{array}{l}\text { Cervical lesion was asymptomatic and } \\
\text { investigation carried out by CBCT. This } \\
\text { imaging modality determines the real extent } \\
\text { and possible point of communication with } \\
\text { periodontal space }\end{array}$ \\
\hline $\begin{array}{l}\text { Ayshe Gulsahi } \\
(2014)^{32}\end{array}$ & $\begin{array}{l}11 \text { cases with a year follow } \\
\text { up period (2005-2013) }\end{array}$ & $\begin{array}{l}\text { Location and progress of a lesion was more } \\
\text { pronounced in CBCT (cone beam computed } \\
\text { tomography) than in a conventional peri apical } \\
\text { radiograph. }\end{array}$ \\
\hline $\begin{array}{l}\text { Akash kumar } \\
\text { Baranwal (2016) }{ }^{27}\end{array}$ & $\begin{array}{l}\text { 23 yr old female with a class } \\
4 \text { lesion in 21. }\end{array}$ & $\begin{array}{l}\text { Treatment by debridement, removal of } \\
\text { granulation tissue followed by root canal } \\
\text { therapy, periodontal flap surgery and } \\
\text { restoration of resorptive defect by Biodentine. }\end{array}$ \\
\hline
\end{tabular}

\section{Conclusion}

Invasive cervical resorption is a rare form of tooth resorption often misdiagnosed as pink tooth (internal resorption). The uniqueness of resorptive process of ICR includes rapid downward progress from the cervical area through gingival margins without involving pulp until in severe form of a lesion. Early identification of this rapidly progressive pathological lesion can result in conservative or non surgical intervention. A progressive lesion of ICR may require a surgical intervention and extraction.

Fruitful outcome of management includes early diagnosis, resorptive process elimination and restorative management. Overall management on diagnosis of ICR is considered on 3 basic treatment choices: ${ }^{28}$

1) Follow up and eventual extraction when tooth becomes asymptomatic

2) Immediate extraction on diagnosis

3) Access gaining, debridement and restoration of resorptive lesion.

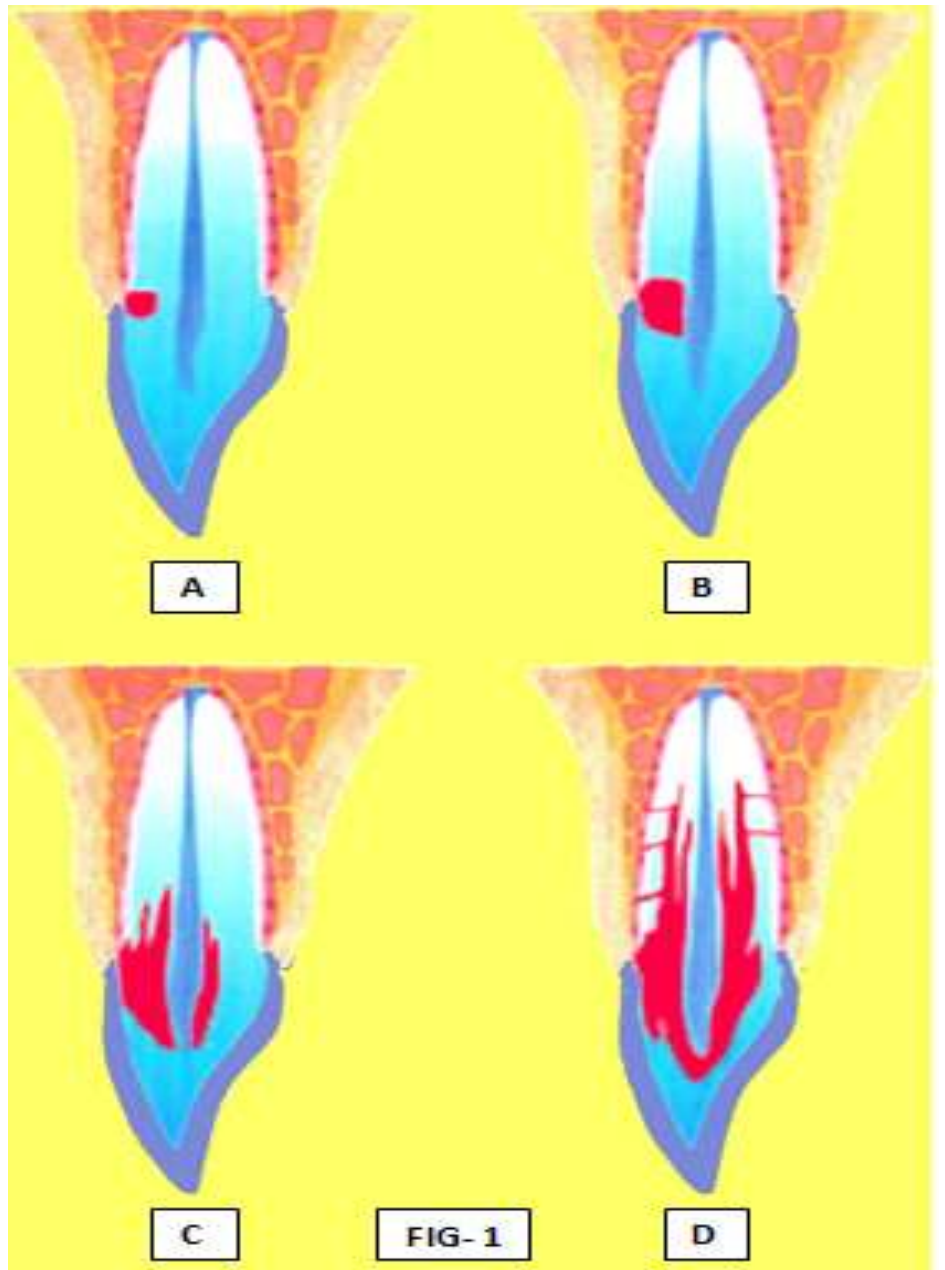

FIG-1: Schematic representation of different stages of progress of Invasive Cervical resorption: A-Class-1 lesion, B-Class-2 lesion, C-Class-3 lesion, D-Class-4 lesion 


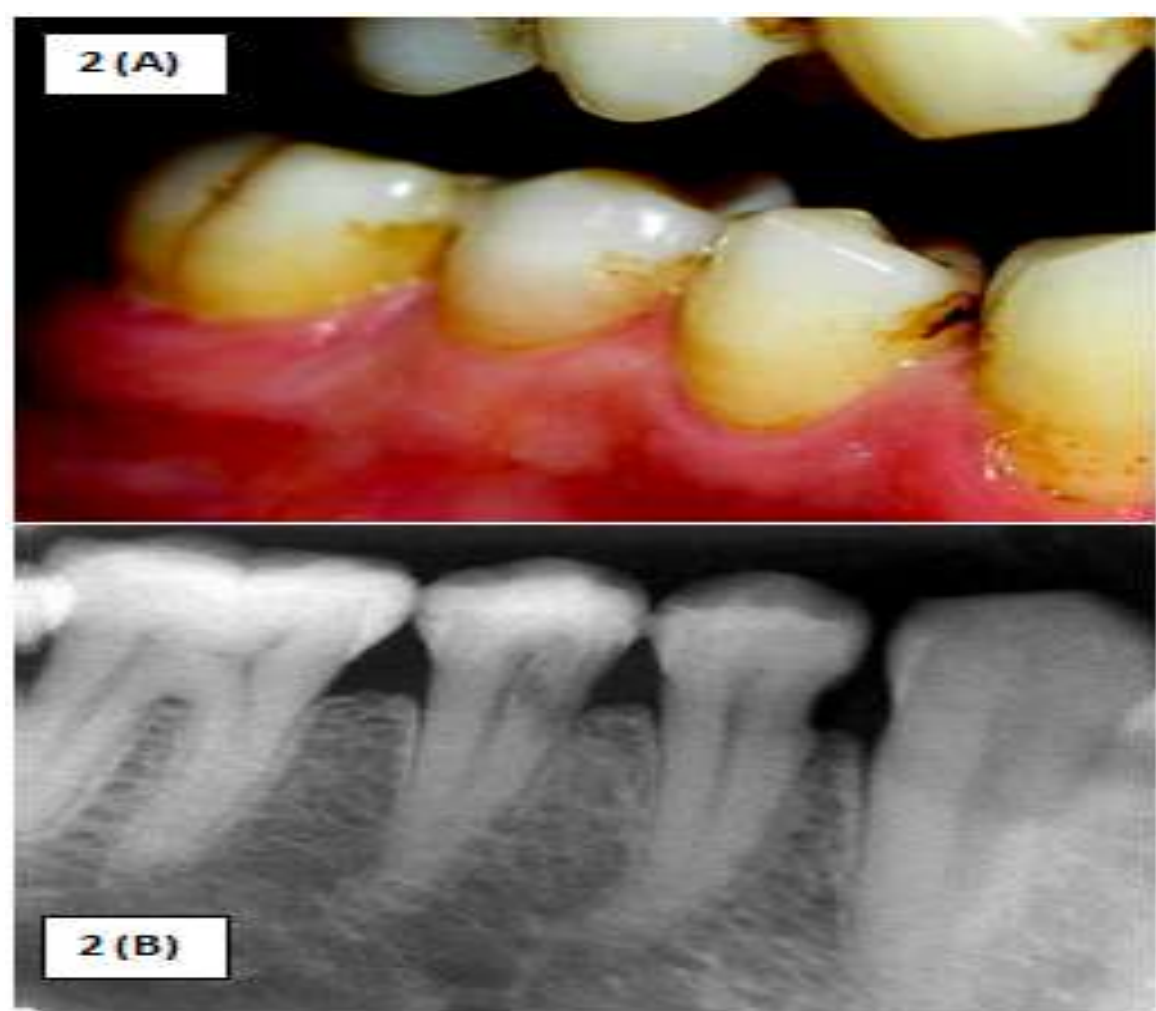

FIG-2: (A) Clinical \& (B) Radiographic representation of a Class-1 Invasive Cervical resorption,

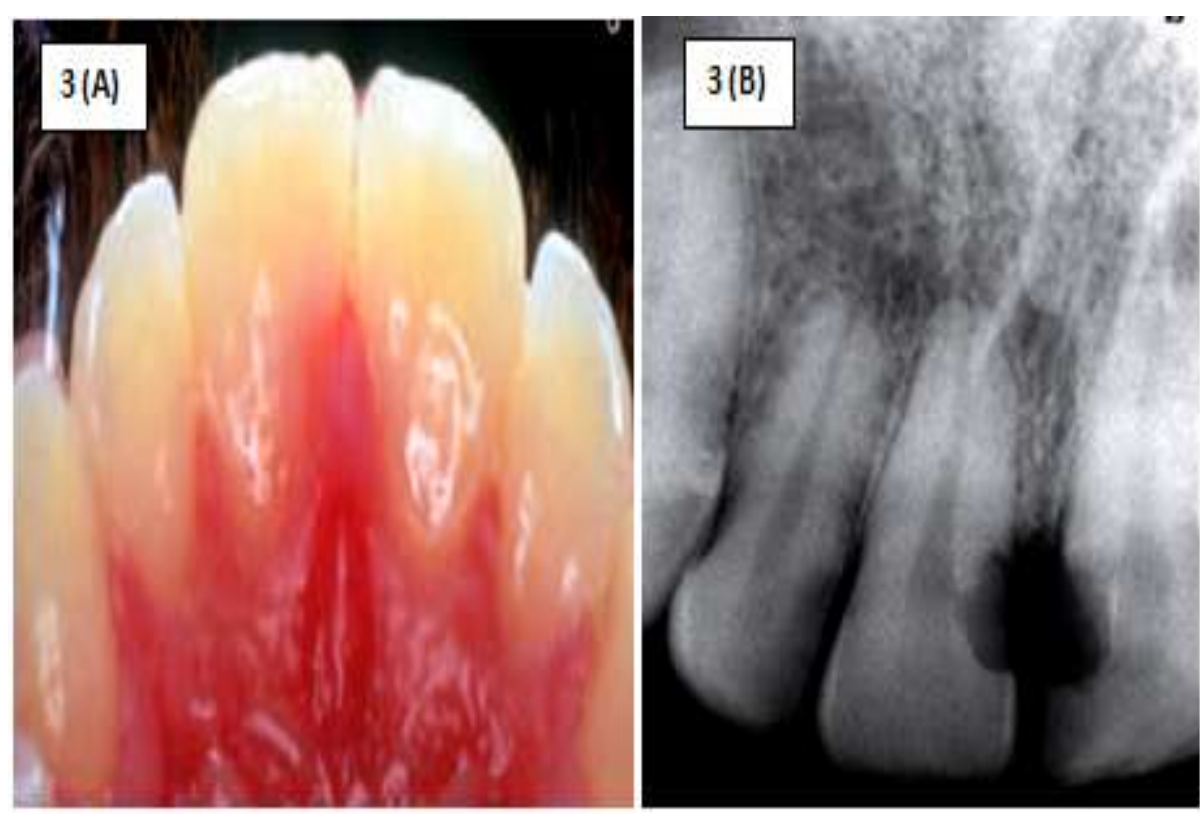

FIG-3: (A) Clinical \& (B) Radiographic representation of a Class-2 Invasive Cervical resorption, 

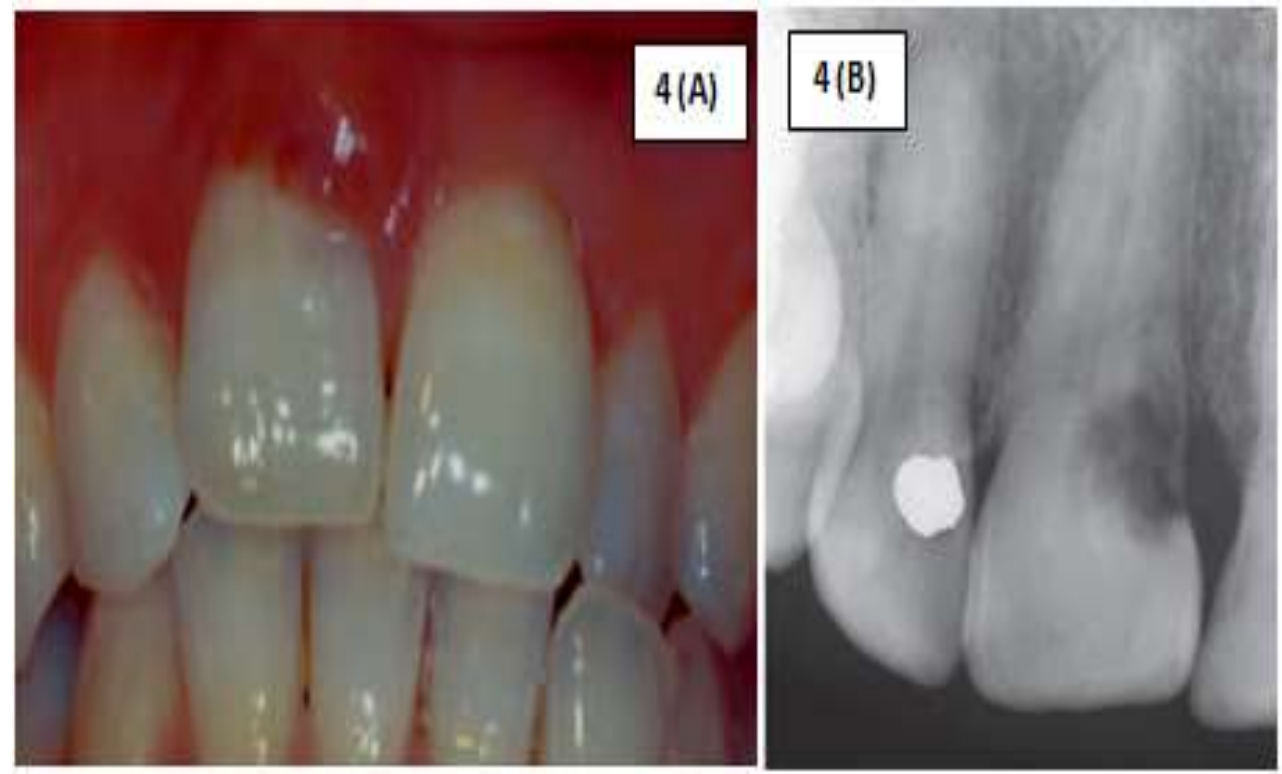

FIG-4: (A) Clinical \& (B) Radiographic representation of a Class-3 Invasive Cervical resorption,
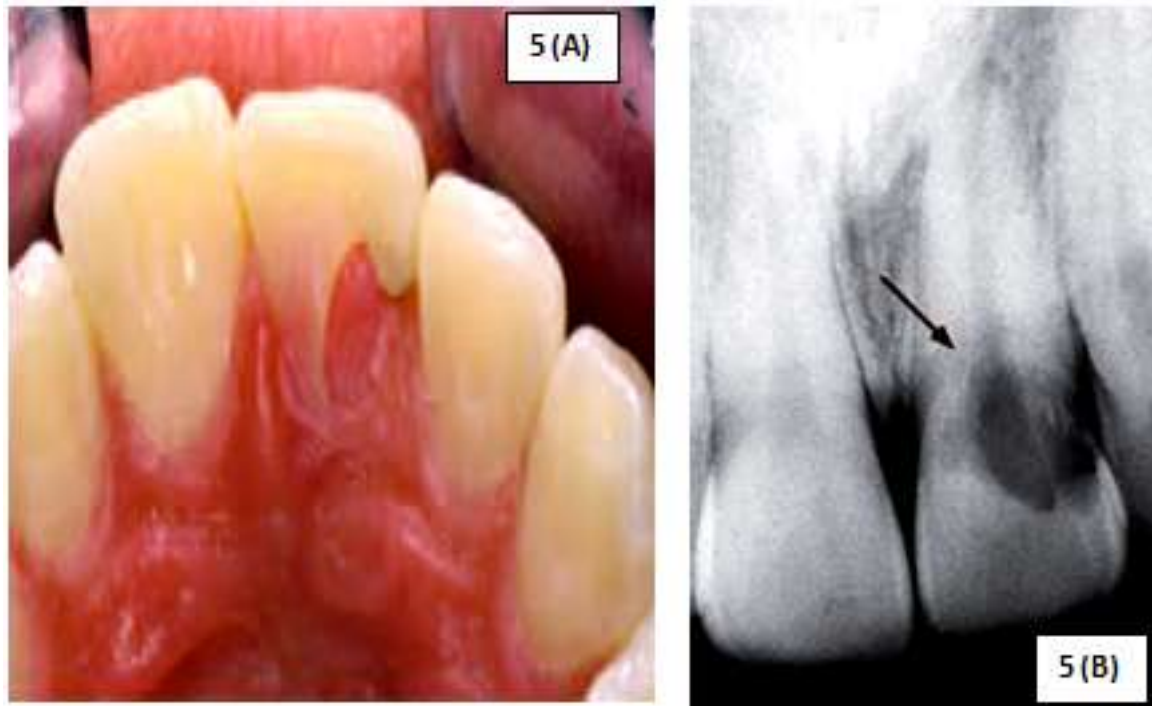

FIG-5: (A) Clinical \& (B) Radiographic representation of a Class-4 Invasive Cervical resorption of 21

\section{References}

[1]. Patel SS, Pitt Ford T. Is the resorption external or internal?. Dent Update 2007; 34: 218-29

[2]. Tronstad L. Root resorption- etiology, terminology and clinical manifestations. Endod Dent Traumatol 1988; 4: 241-52

[3]. Heithersay G. Invasive cervical resorption. Endod Topics 2004; 7: 73-92.

[4]. Gaskill JH. Report of a case of internal resorption. Dental Cosmos 1894; 36: 1019-1024.

[5]. Mummery JH. The pathology of "pink spots" on teeth. Br Dent J 1920; 41: 301-311.

[6]. Geoffrey S. Heithersay. Clinical, radiologic and histopathologic features of Invasive cervical resorption. Quintessence International 1999; 30:27-37.

[7]. John J. Stropko. Invasive cervical resorption (ICR): A description, diagnosis and discussion of optional management- A review of four long term cases. CE article_ Invasive cervical resorption: 6-20.

[8]. Luso S, Luder HU. Resorption pattern and radiographic diagnosis of invasive cervical resorption. Schweiz Monatsschr Zahnmed 2012; 122: 914-922

[9]. Patel S, Dawood A. The use of cone beam computed tomography in the management of external cervical resorption lesions. International Endodontics Journal 2007;40: 730-737.

[10]. Coyle M, Toner M, Barry H. Multiple teeth showing invasive cervical resorption- an entity with little known histologic features. Journal of Oral Pathology \& Medicine. 2006;35: 55-57.

[11]. Harrington GW, Natkin E. External resorption associated with bleaching of pulpless teeth. J Endod 1979; 5: $344-348$

[12]. Heithersay GS, Dahlstrom SW, Marin PD. Incidence of invasive cervical resorption in bleached root-filled teeth. Aust Dent J 1994; 39:82-87

[13]. Heithersay GS. Invasive cervical resorption: an analysis of potential pre disposing factors. Quintessence Int 1999; 30: 83-95

[14]. V Gunst, B. Huybrechts. Playing wind instruments as a potential aetiologic cofactor in external cervical resorption: two case reports. International Endodontic Journal 2011; 44: 268-282 
[15]. Geoffrey S Heithersay. Treatment of invasive cervical resorption: an analysis of results using topical application of trichloracetic acid, curettage, and restoration. Quintessence Int 1999; 30: 96-110

[16]. Wedenberg C, Lindskog S. Evidence for a resorption inhibitor in dentin. Scand J Dent Res 1987; 95: 270-71

[17]. Trope M. Root resorptionof dental and traumatic origin: classification based on etiology. Pract Periodont Aesthet Dent 1998; 10:515-522

[18]. Levin L, Trope M. In: Hargreaves KM, Goodis HE, eds. Seltzer and Bender's Dental pulp, revised edition. Quintessence Publishing Co, Inc, Chicago, London, 2002: 425-447.

[19]. Karla de Faria Vasconcelos, Yuri Nejaim. Diagnosis of Invasive cervical resorption by using cone beam computed tomography: Report of two cases. Brazillian Dent J 2012; 23(5): 602-607

[20]. Ikhar A, Thakur N, Patel A. Management of external invasive cervical resorption tooth with mineralised trioxide aggregate: A case report. Case Rep Med 2013;2013: 139801

[21]. Cohen S, Hargreaves KM, Berman LH. Cohen's pathways of the pulp. $10^{\text {th }}$ ed. St.Louis, MO: Mosby; 2010. p.605

[22]. Frank AL, Torabinejad M. Diagnosis and treatment of Extra-canal invasive resorption. J Endod 1998;24: 500-504

[23]. Kim Y, Lee CY, Kim E, Roh BD. Invasive cervical root resorption: treatment challenges. Restor Dent Endod 2012; 37(4): 228-31

[24]. Kerr DA, Courtney RM, Burkes EJ. Multiple idiopathic root resorption. Oral surgery, Oral medicine \& Oral pathology 1970; 29: 552-65

[25]. Moody GH, Muir KF. Multiple idiopathic root resorption: a case report and discussion of pathogenesis. Journal of Clinical Periodontology 1991; 18: 577-80

[26]. Matsui K, Echigo S. A Case of multiple idiopathic root resorption- treatment by impacting tooth root. Journal of the Japanese Stomatological Society 1998; 47: 68-75

[27]. Akash Kumar Baranwal. Management of external invasive cervical resorption of tooth with Biodentine: A case report. Journal of Conservative Dentistry 2016; 19: 296-9

[28]. Schwartz RS, Robbins JW. Management of invasive cervical resorption: observations from three private practices and a report of three cases. J Endod 2010; 36: 1721-30

[29]. Moskow BS. Periodontal manifestations of hyperoxalouria and oxalosis. J Periodontol 1989; 60: 271-8

[30]. Neely AL, Gordon SC. A familial pattern of multiple idiopathic cervical root resorption in a father and son: a 22 year follow up. $\mathbf{J}$ Periodontol 2007; 78: 367-71

[31]. Liang H, EJ Burkes, NL Frederiksen. Systematic review: Multiple idiopathic cervical root resorption: systematic review and report of four cases. Dentomaxillofac Radiol 2003; 32: 150-55

[32]. Ayshe Gulsahi. Clinical and radiological appearances of invasive cervical resorption. OHDM; 13(4): 934-39.

[33]. V.S.H. Yu, H.H. Messer et al. Multiple idiopathic cervical resorption: case report and discussion of management options. International Endodontic Journal 2011; 44: 77-85

[34]. R. Pace, V. Guillani \& G. Pagavino. Mineral trioxide aggregate in the treatment of external invasive resorption: a case report. International Endodontic Journal 2008; 41: 258-266 